
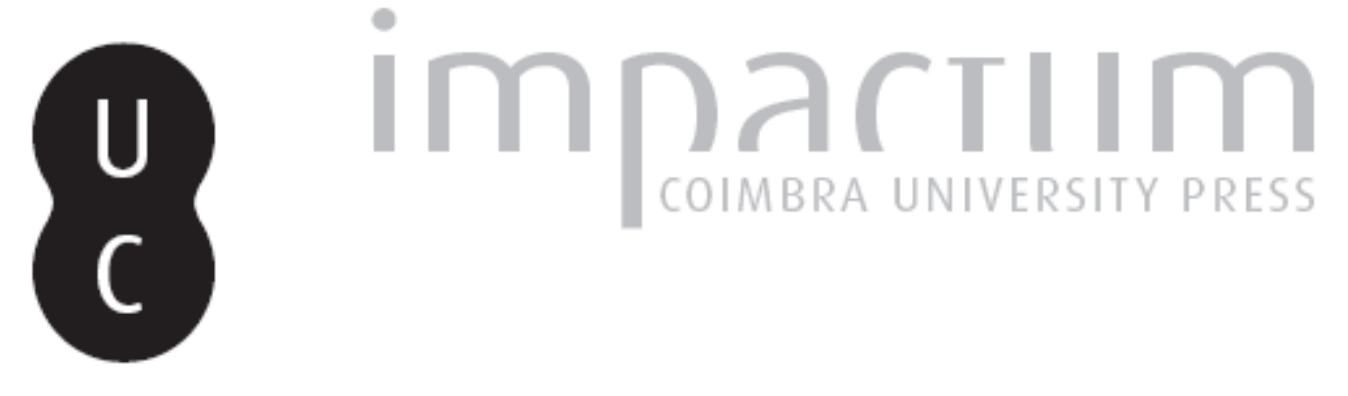

A complexidade da conjuntura (século XXI) e o futuro imprevisível (2014)

Autor(es): $\quad$ Moreira, Adriano

Publicado por: Centro de Informação Europe Direct de Aveiro; Centro de Estudos

Interdisciplinares do Século XX

URL

persistente:

URI:http://hdl.handle.net/10316.2/33972

DOI:

DOI:http://dx.doi.org/10.14195/1647-6336_11_1

Accessed : $\quad$ 26-Apr-2023 13:08:25

A navegação consulta e descarregamento dos títulos inseridos nas Bibliotecas Digitais UC Digitalis, UC Pombalina e UC Impactum, pressupõem a aceitação plena e sem reservas dos Termos e Condições de Uso destas Bibliotecas Digitais, disponíveis em https://digitalis.uc.pt/pt-pt/termos.

Conforme exposto nos referidos Termos e Condições de Uso, o descarregamento de títulos de acesso restrito requer uma licença válida de autorização devendo o utilizador aceder ao(s) documento(s) a partir de um endereço de IP da instituição detentora da supramencionada licença.

Ao utilizador é apenas permitido o descarregamento para uso pessoal, pelo que o emprego do(s) título(s) descarregado(s) para outro fim, designadamente comercial, carece de autorização do respetivo autor ou editor da obra.

Na medida em que todas as obras da UC Digitalis se encontram protegidas pelo Código do Direito de Autor e Direitos Conexos e demais legislação aplicável, toda a cópia, parcial ou total, deste documento, nos casos em que é legalmente admitida, deverá conter ou fazer-se acompanhar por este aviso.

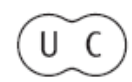


DEBATER

A EUROPA

jul-dez 2014

QUE EUROPA(S)?

CONTEXTOS E DESAFIOS 


\title{
A complexidade da conjuntura (século XXI) e o futuro imprevisível (2014)
}

\author{
ADRIANO MOREIRA \\ Presidente do Instituto de Altos Estudos \\ da Academia das Ciências de Lisboa \\ Presidente do Conselho Geral \\ da Universidade Técnica de Lisboa \\ E-mail: amoreira@acad-ciencias.pt
}

\section{Resumo}

Depois das grandes guerras (1914-1918, 1939-1945) as potências ocidentais guiaram-se pelo conceito de terem ganho as guerras, quando apenas não as tinham perdido. Rapidamente, a ordem militar (NATO - VARSÓVIA) substituiu a eficácia da Carta da ONU, embora as organizações especializadas, como a UNESCO, tenham prestado grandes serviços. O fim da guerra fria, vigente durante meio século, não impediu que a maior parte dos membros da ONU sejam Estados incapazes de enfrentar os brutais desafios da natureza, nem que a pobreza invadisse o norte do Mediterrâneo, ou que a privatização da guerra criasse a nova categoria da guerra dos povos. O relativismo invadiu o Ocidente, o credo do mercado parece patrocinar uma nova luta pela hegemonia, o que tudo já foi avaliado como traduzindo um risco mundial tão grave como o confronto atómico. O impossível espera por uma oportunidade.

Palavras-chave: I Guerra Mundial; II Guerra Mundial; NATO; VARSÒVIA; ONU; UNESCO

\footnotetext{
Abstract

After the great wars (1914-1918, 1939-1945), Western powers were guided by the concept of having won the war, when only they did not lose them. Quickly, the military order (NATO WARSAW) replaced the efficacy of the UN Charter, although specialized agencies such as
} 
UNESCO, have rendered great services. The end of the cold war, which lasted for half a century, did not prevent that the majority of UN members are States unable to face the brutal challenges of nature nor that poverty invaded the north of the Mediterranean, or that the privatization of war created the new category of war of people. The Relativism invaded the West, the creed of the market seems to sponsor a new struggle for hegemony, which has already been reported as a global risk as serious as the atomic confrontation. The Impossible is waiting for an opportunity.

Keywords: World War I; World War II; NATO; Warsaw; UN; UNESCO

O discurso político corrente foi escrito no século $\mathrm{XX}$, na época em que a guerra fria era a definição de ameaça mais evidente à paz imperfeita com que findara a guerra de 19391945, e a ONU a definição da ordem imaginada para que não voltasse a acontecer uma catástrofe igual.

A mudança do Milénio tornou evidente a persistência de um fenómeno recente na vida política, interna e internacional, que é da imagem do poder perdido se manter orientadora dos responsáveis, enquanto a realidade cresce de complexidade a exigir uma nova racionalização que chega, quando a complexidade consegue ser ultrapassada, tarde para evitar os acidentes que entretanto atingem a integridade dos valores humanos e materiais, neste caso do património comum da Humanidade.

Logo na Carta da ONU o Conselho de Segurança distinguiu com o poder de veto cinco países, dos quais a França e a Inglaterra, tinham perdido as exigências do qualificativo de grandes potências, e a China não era pressentida como um dos poderes emergentes, sendo ficticiamente representada pela ilha de Taiwan.

Os conceitos de soberania dos Estados, de jurisdição interna, de nacionalidade, de democracia, supostos continuarem a fazer parte do conjunto de valores que inspiram, com diferenças temporais, geográficas, e culturais, as construções jurídicas que, na observação de John Rawls (Theorie of Justice, 1971), estendem um "veil of ignorance" sobre a realidade nova, anunciada pela guerra, mas não lida pelas incorporadas teorias da "rational choice".

Não obstante os grandes serviços prestados à humanidade pelas organizações especializadas da ONU, os factos desenvolveram uma interdependência global de todos os seres humanos, sem que a estrutura jurídica da Carta da ONU disciplinasse o seu desenvolvimento. 
Em primeiro lugar, o movimento da descolonização, sem o pacifismo previsto, designadamente na Argélia, no Vietnam, na Coreia, nas colónias portuguesas, na separação da União Indiana do Paquistão, na instalação de Israel, no Congo Belga, todavia implicou que, pela primeira vez na história, todas as áreas culturais do mundo falaram com voz própria na cena internacional, com leituras próprias dos textos que apenas os ocidentais tinham escrito ao fundar a ONU.

Por muito que o adiantamento científico e tecnológico dos ocidentais os distanciasse desses povos que antes tratavam como o resto do mundo, tal distância não evitou o facto de os extintos poderes imperiais, ao retirarem, com ordem ou em desordem, também ficassem dependentes das matérias-primas, das energias não-renováveis, e até no que toca à autonomia alimentar, cujo domínio alimentou as ambições expansionistas do século XIX: dominar as fontes de matérias-primas e os mercados de produtos acabados.

As diferenças de leituras, apoiadas em constelações diferenciadas de valores identificadores de cada área, podem referir-se a uma premissa ocidental essencial que são os direitos humanos.

De acordo com a leitura de Donnelly, “o verdadeiro sentido da expressão direitos humanos indica simultaneamente a sua natureza e as suas fontes: são direitos que cada um tem pelo simples facto de que é humano. São titulados por qualquer ser humano, independentemente de quaisquer direitos ou deveres que possam (ou não possam) ter como cidadãos, membros de famílias, trabalhadores, ou membro de qualquer organização pública ou privada. Na linguagem da Declaração de 1948, são direitos universais". ${ }^{1}$ É certo que à efectividade da Declaração foi crescendo de abrangência real, mas é extremamente relevante, vista a situação que a dimensão da pobreza mundial abrange, que isso não obsta a que vários Estados, incluindo a China, a Indonésia, Singapura, a considerem um produto ocidental não aplicável internamente no âmbito dos seus territórios e populações. O ano de 1989, a que pertence a intervenção brutal contra os estudantes na Praça de Tiananmen, em Pequim, ficou como referência das diferenças de leitura. O terrorismo iniciado no 11 de Setembro contra as

\footnotetext{
${ }^{1}$ Joël Andriantsimbazovina (et all), Dictionnaire des droits de l'homme, PUF, Paris, 2008. Jack Donnelly, International Human Rights, Boulder. CO: Westview Press, 1999. David P. Forsyth, The internalization of Human Rights, Lexington, MA: Lexington Books. Human Rights Watch Word Reports (annual), New York, Human Rights Watch.
} 
Torres Gémeas de Nova York, demonstrou que a leitura ocidental, designadamente dos EUA, pode variar. $^{2}$

Uma das grandes tarefas foi, sem esquecer o colonialismo opressor, e sem esquecer o horror da guerra mundial, pela qual foram responsáveis os demónios europeus, sobretudo arregimentados mais uma vez pela Alemanha, transformar esse sofrimento em sabedoria para tentar efectivar um projecto de ordem mundial que evitasse a catástrofe.

Como escreveu o notável Victor Klemperer, na sua carta de 6 de Janeiro de 1947, dirigida a Hans Hiroche, um responsável envolvido no nazismo: “vós dizeis que vós e os vossos camaradas esperáveis, continuando no vosso posto, atenuar a loucura do regime... Não quero, no que vos respeita, erigir-me em juiz. Mas, eu e a minha mulher, tivemos sempre bastante simpatia por vós e não vos consideramos capaz de violência. Estamos igualmente convencidos que trabalhareis sinceramente para reconstruir a Alemanha e que, considerando a vossa cultura e capacidades podereis dar grande contributo". 3

Não podem ignorar-se os benefícios que todos os povos ficaram a dever à intervenção das Organizações especializadas da ONU, mas o facto, complexo, e de prognóstico inseguro quanto ao futuro, é que o presente dá sinais de um desastre total eminente.

Não é que o problema da paz e da guerra não tenha continuado a estar excessivamente presente, e começar pela inquietação com a proliferação das armas de destruição maciça, deixando de ser um problema exclusivamente do foro de políticos e militares, a começar pelo facto de que para o investimento os fundos são desviados de responsabilidades do desenvolvimento sustentado e da segurança humana, tanto importando que se trate de proliferação vertical das potências tradicionais, como da proliferação horizontal de armas convencionais abrangente de países de escassos recursos, como de qualquer das proliferações na área das armas de destruição maciça. Logo no primeiro uso das armas atómicas pelos EUA contra o Japão em 1945, se tornou evidente a necessidade e urgência de um movimento contra a proliferação. Quando em 1968 foi aberto à assinatura o The Non-Proliferation Treaty, abrangendo a vertical e a horizontal, tendo como fim último terminar com a existência de armas de destruição maciça, também se abriu caminho à proibição de armas biológicas, Tratado assinado em 1972, mas os resultados foram exíguos. E deram lugar à negociação

\footnotetext{
${ }^{2}$ Priscilla D. Haynes, Unspeakable Truth; Confronting State Terror and Atrocity, Rutledge, Nova York, 2001.

${ }^{3}$ Victor Klemperer, Mes soldats de papier, Je veux témoigner jusque au bout, Journal 1942-1945, 2. ${ }^{\circ}$ vol., pg. 977, Editions du Seuil, Paris, 2000.
} 
entre duas superpotências, EUA e URSS, que assinaram o SALTI, limitando as armas estratégicas, o ABM limitando a suas bases antimísseis, seguindo-se uma série de acordos incluindo, em 1996, o Comprehensive Nuclear Test Ban Tracty, o que não impediu a rivalidade, neste domínio, do Paquistão e da União Indiana.

Se a queda da URSS colocou um ponto final na guerra fria, e deste modo na ordem militar que suplantou por meio século as promessas da Carta da ONU, o credo do mercado não impediu que a Rússia, o Japão, a França, os EUA, a Inglaterra, a Alemanha Federal, o Canadá, estabelecessem uma inquietante regulação, em 1976, para definir a lista dos comerciáveis (London Club), o que foi completado, em 1980, pelo Missile Technology Control Regim, de limitada eficácia. De facto trata-se de um percurso que mantém validade à sentença de Sarte, no sentido de que a humanidade tem nas suas mãos "o poder de decidir continuar ou morrer". 4

Embora o globalismo chamasse as atenções de analistas e governantes, o nacionalismo pareceu fazer multiplicar os sentidos do conceito, e, ainda quando não ofensivo, ser uma arma ideológica de defesa contra as interdependências. No mais antigo sentido, que é europeu e americano, e teve em Napoleão pelo menos o mais visível introdutor do nacionalismo cívico, isto na conclusão de André Malraux, que viu como elemento essencial do bonapartismo a unidade coerente dos franceses. Depois da guerra de 1914-1918, o princípio de Wilson da necessária coincidência entre Nação e Estado, apoiou a importância do sentido de identidade, de pertença, e lealdade à comunidade nacional, e à sua soberania e independência, e progresso.

Mas a descolonização implicou a importância de um nacionalismo étnico, com tradição em países europeus, e, com o sentido de "associação ancestral", foi adoptado por territórios que se tornaram independentes, e a sua relação com o nacionalismo cívico tem limites. De qualquer modo, as identidades parciais dentro do Estado plural, não se identificam necessariamente com a pertença e fidelidade a um Estado que lhes exige civismo, assim como ideologias glorificadoras do Estado, ou a hipervaloração de identidades religiosas, continuam como causas de rupturas da paz, de que foram exemplo, na mudança de

\footnotetext{
${ }^{4}$ Jack Mendelsohn, Is Arms Control Dead?, Issus in Science and Technology, n. ${ }^{\circ}$ 3, 2001. Scott D. Sagan and N. Kenneth N. Waltz, The spread of nuclear Weapons: A Debate, 1995, W. W. Norton, Nova York. Aaron Kath, The Arms Trade Revolution. The Major Impact of Small Arms, Washington Quarterly, 1994.
} 
século, a destruição da Jugoslávia, o conflito Israelo-Árabe, a dissolução da URSS, e numerosos conflitos nas antigas áreas coloniais. ${ }^{5}$

Tudo implicou uma espécie de anarquia no entendimento e execução dos direitos humanos e do regime político responsável, que os ocidentais entenderam ser a democracia, apoiados na Magna Carta (1215), na Declaração de Direitos da Revolução Francesa (1789) e o U. S. Bill of Rights (1791). A ONU entendeu ter-lhe dado uma definição em 1948 com a sua Declaração Universal de Direitos Humanos, mas chegou à mudança do século, entrando no novo Milénio, sem governança da globalidade.

Com os seus fundamentos de Peacekeeping e Peacemaking, o activo da ONU é muito inferior ao passivo avaliado depois do fim da guerra fria. Na conclusão de Carolyn M. Stephenson, "perhaps the dilemmas the UN faces would not be so difficult if international system were not so biased toward the utility of violent force. The efficacy of violence is a myth: at best, only some win-and at great expenses of others. Because violent force does not make peace or justice, its use by the UN would not seem to be the must effective use of its limited resources". 6

A queda do Muro de Berlim, em 1989, marca uma queda da ordem militar do globo, por extinção do Pacto de Varsóvia, mas não o regresso à integridade do programa normativo da ONU, antes a uma acelerada implantação do credo do mercado, sem regulação, muito apoiado pela deriva dos EUA para o unilateralismo republicano, este convicto de alguns princípios: que a América é a Nação indispensável ao mundo, como que a casa no cimo da colina; que o seu interesse nacional permanente, embora de conteúdo variável, é intocável; que o mundo deveria organizar os poderes políticos pelo modelo democrático tendencialmente orientado pela Declaração americana de direitos; que o mercado livre deveria ser o sistema da economia global. ${ }^{7}$

Uma das deploráveis consequências desta posição, para além das guerras como a do Iraque e do Afeganistão, foi a deriva militar para o outsourcing, a privatização da guerra com o seu cortejo de desastres humanos produzidos designadamente nas áreas da pobreza, incluindo o

\footnotetext{
${ }^{5}$ Eric Hobsbawm, Nations and Nationalism since 1780: Programme, Myth, Reality, Cambridge University Press, N. Y., 1992. C. Taylor, Multiculturalism, Flammarion, Paris, 1997. Cahiers Français, Citoyenneté et Société, Maio - Junho, 1997. W. Kyrlieka, La cieyenneté multiculturelle, La Découvert, Paris, 2001.

${ }^{6}$ Carolyn M. Stephenson, Peacekeeping and Peacemaking, in M. T. Snarr e D. N. Snarr (coord.), Introducing Global issues, Lynne Rienner Publishers, Londres, 2002, pg. 85.

${ }^{7}$ Le Nouvel état du monde, 80 idées - forces pour entrer dans le 21. ${ }^{\circ}$ siècle, La Découvert, Paris, 1999, passim.
} 
contingente variado de crianças envolvidas em combates, com os EUA aparentemente dominados por um complexo militar-industrial a que se referia Eisenhower no seu Farwel Adress, e que confessou não ter podido dominar.

Por muito que a ONU periodicamente afirme a sua determinação de realizar os Objectivos do Milénio, o certo é que a pobreza se tornou um desafio angustiante, e que aquilo que Josué de Castro chamou, já em meados do século XX, a geografia da fome, com a fronteira começando abaixo do Saara, se tornou verbalmente amenizada em fronteira da pobreza, que atravessou o Mediterrâneo e atinge parte da Europa e grande parte da população dos EUA. ${ }^{8}$ Como escreveu Benjamim Barber, “ a influência das corporações multinacionais, a obsessão com o livre comércio, e o aparecimento de um global, computorizado, e economicamente mercado de massas, estão destruindo as fronteiras entre as populações e afectando as soberanias das mais pequenas, ou menos desenvolvidas nações". 9 A sua conclusão é a de um mundo crescentemente estandartizado, um mundo culturalmente dominado por governos, quase todo-poderosos, agentes e produtores de bens de consumo. $\mathrm{Na}$ minha síntese, um mundo em que o credo do mercado substitui o valor das coisas pelo preço das coisas, com uma desordem global”.

Houve um momento de grande esperança mundial quando Obama ganhou a presidência dos EUA, prometendo uma reformulação total do unilateralismo republicano, uma abertura ao Estado social das tradições socialista democrática e social da Igreja. O peso da estrutura herdada, que significa um envolvimento no complexo militar industrial, tem todavia conduzido os EUA a uma situação em que se manifesta a fadiga dos metais que atinge os impérios, e torna evidente que é a decadência ocidental que exige atenção e política. ${ }^{10}$

O facto é que a ordem jurídica concebida em s. Francisco, ela própria apoiada numa visão ultrapassada da realidade, foi sendo posta em suspenso. Não foi apenas o facto de a ordem militar dos Pactos ter vigorado, à margem dela, durante cerca de meio século da guerra fria. Foi ainda que se agravou a circunstância frequente de a imagem da realidade ter persistido colocando a mudança sob um véu de ignorância, com os cinco grandes do Conselho

\footnotetext{
${ }^{8}$ Jean Drêse e Amartya Sen, Hunger and Public Action, Oxford, Clarendon Press, 1989. U. N. Development Programme (anual).

${ }^{9}$ Benjamim Barber, "Jihad vs. Mc World", Atlantic Monthly, March, 1996.

${ }^{10}$ Barack Obama, "Renewing American Leadership", Foreign Affairs, Julho - Agosto, 2007. Robert Kogan, "Foreign Policy Sequels, Washington Post, 9 de Março de 2009. Adam Posen, Le rôle du dollar", entrevista, Le Monde, 31 de Março de 2009. Philippe Droz-Vicent, Faillite des Think Tanks americains?, in Le Grand Tourant?, L'État du Monde, La Découverte, Paris, 2010.
} 
de Segurança a supor, como a França e a Inglaterra, de que continuavam a possuir uma capacidade mundial, com a URSS e, mais tarde, os EUA a ignorarem o declínio de estatuto, e o mundo a ser submetido a poderes não institucionais, nem sempre identificáveis. O poder da informação com privilégios não limitados pela lei, a privatização da defesa a multiplicar a criminalidade de guerra, designadamente o uso das crianças nos combates, os poderes atípicos a desafiarem os Estados, e o poder financeiro a conduzir a ordem mundial para a final crise financeira e económica que chega à área da fronteira da pobreza. $\mathrm{O}$ relativismo invadiu o Ocidente, e a natureza da complexidade tornou-se o paradigma que domina os desafios e as respostas à exigência de uma nova ordem, numa data em que a crise mundial financeira e económica alarga a distância entre povos ricos e povos pobres, um facto que já foi avaliado como traduzindo um risco mundial tão grave como o desafio do confronto atómico. ${ }^{11}$

\footnotetext{
${ }^{11}$ Bread for the World Institute. Annual Report on the State of World Hunger. Washington, DC: BFW Institute. Jean Dréze e Amartya Sen, Hunger and Public Action, Clarendon Press, 1989, Oxford. Louis Gill, États en faillite: le fin du "miracle libéral", in Le Grand Tournant?, L'État du Monde, Paris, 2010, pg. 124. Jean de Maillard, Les trois âges de la piraterie financière, idem, pg. 130. Jean Ziegler, L'Impire de la honte, Fayard, Paris, 2005.
} 